\title{
Nurturing Girls' Interest in Science with Particle Physics Masterclasses
}

\author{
Uta Bilow ${ }^{a, *}$ on behalf of IPPOG (International Particle Physics Outreach Group) \\ ${ }^{a}$ Technische Universität Dresden, Institute for Nuclear and Particle Physics \\ 01062 Dresden, Germany \\ E-mail: uta.bilowetu-dresden.de
}

To help boost the number of women entering physics careers, the well-established program International Masterclasses is holding special events on the UN International Day of Women and Girls in Science (February 11). Girls aged 15-19 participate in a Masterclass under the supervision of female facilitators, who serve as role models. Particle Physics Masterclasses, organized by the International Particle Physics Outreach Group (IPPOG), are a proven tool to engage high school students with particle physics. In a Masterclass, participants learn about high energy physics in a day-long course and perform a tailor-made physics analysis with real LHC data. In 2020, universities and research labs organized 17 Masterclasses for girls, with participation from three continents. About 600 girls attended the Masterclasses. Videoconferences with CERN were held where the girls could talk to CERN women scientists and learn about the careers of these role models.

40th International Conference on High Energy physics - ICHEP2020

July 28 - August 6, 2020

Prague, Czech Republic (virtual meeting)

*Speaker 


\section{Introduction}

Particle Physics Masterclasses are a proven tool in HEP outreach to engage high school students with high energy physics. A Masterclass is a day-long activity, where high school students are invited to a research lab or university to step in the shoes of a particle physicist. Participants learn about high energy physics in a day-long course and perform a tailor-made physics analysis with real data from LHC experiments or others. Since a few years, the International Particle Physics Outreach Group (IPPOG) is organizing additional Particle Physics Masterclasses targeting especially girls. These events take place each year on Feb 11, the UN International Day of Women and Girls in Science, with the aim to nurture girls' interest in science and encourage them to pursue a career in physics, where gender ratios are still woefully unbalanced.

\section{Particle Physics Masterclasses}

In a Particle Physics Masterclass, high school students follow in the footsteps of a scientist and not only listen to lectures but do a hands-on activity, working shoulder to shoulder with and using the same methods and tool as the scientist [1]. Students perform measurements and work with real data collected by experiments at the LHC or Belle II or MINERvA. The results of these analyses are then discussed and combined in a videoconference, where up to five groups from different countries participate - this conveys the international spirit of particle physics. In addition, a particle therapy Masterclass has been developed, in order to highlight some of the benefits for society from the technology developed for particle physics research. Videoconferences are hosted at CERN, Fermilab, GSI, KEK, or TRIUMF, and they are mostly moderated by young scientists.

Particle Physics Masterclasses take place in large numbers as part of the "International Masterclasses" program (IMC) [2]. The program attracts each year more than 14,000 high school students in 60 countries, thus offering them the chance to close their textbooks and experience modern science first-hand. IMC is organized by the International Particle Physics Outreach Group (IPPOG) [3], a unique network of scientists, educators and communication specialists working across the globe in informal science education and outreach for particle physics with the motivation to inspire the next generation of scientists.

\section{Gender balance in physics}

Physics is a field in which gender ratios are not balanced. At many career levels, women are significantly less represented than men. The number of women with a physics bachelor was $22 \%$ in 2018, according to the Statistical Research Center of the American Institute of Physics [4]. Women with a PhD in physics made up $20 \%$ in 2017 [5]. The reasons for this imbalance are manifold. Physics is viewed by society as hard and difficult. In a recent study, Archer et al. discuss the evidence of a "physics habitus that was strongly aligned with notions of intelligence/cleverness and masculinity and identifies how young women were particularly disadvantaged by a popular notion of the 'effortlessly clever physicist'" [6]. The social 
conditioning of boys and girls, which starts early, does not encourage girls to pursue a career in STEM related fields.

\section{Masterclasses on the International Day of Women and Girls in Science}

Gender inequalities in physics and other STEM related fields have motivated the United Nations General Assembly to adopt a resolution on 22 December 2015 and declare 11 February as the International Day of Women and Girls in Science (IDWGS) [7]. Education and awareness-raising activities are encouraged on this date to support and promote the full and equal participation of women and girls in science education and research activities.

To help boost the number of women entering physics careers and to offer girls additional opportunities to collect positive experiences in this field, IPPOG decided to hold special Masterclass events on the IDWGS. This effort started in 2017 [8]. All research labs participating in the regular International Masterclasses program were invited to organize a Masterclass targeting especially girls. 10 research labs followed this call and held an event. Because 11 February was a Saturday, it was difficult for some institutes to hold an event on that day. Therefore activities started already on 10 February and continued on Saturday. A total of 320 girls attended these Masterclasses, a few of which were not exclusively, but also open to boys. All institutes engaged female lecturers and tutors for these Masterclasses, as much as possible, to provide role models for the girls. In addition, all videoconferences held with CERN had female moderators.

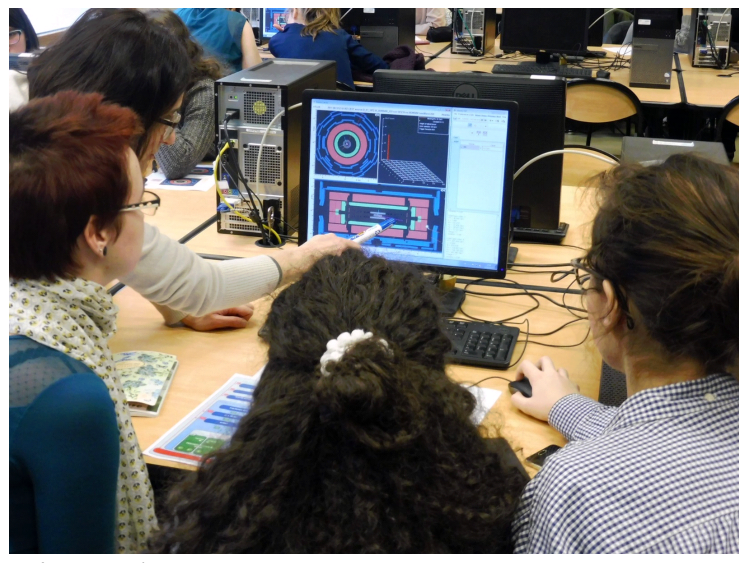

Figure 1: Girls' Masterclass 2017 at APC Paris

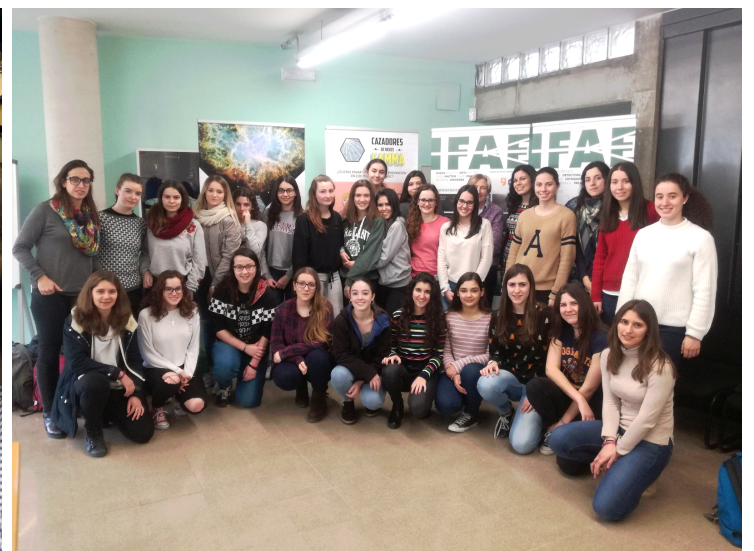

Figure 2: Group picture from 2017 at IFAE Barcelona

In 2018, when February 11 was a Sunday, Masterclasses for girls were offered on Monday, February 12. Eight research labs participated and organized Masterclasses with a total of 250 students [9]. The next year, 11 research labs organized Masterclasses on IDWGS, of which 9 were targeting girls only. 3 videoconferences with 7 female moderators were held to offer all groups a connection with female researchers at CERN [10].

\subsection{Edition}

In 2020, we saw a record participation in the program [11]. 17 research groups followed the call, and a total of 600 students participated in the girls' Masterclasses. ATLAS Z path Masterclasses were held at IFAE Barcelona, University of Heidelberg, Lancaster University, 
CTU Prague, and IFIC Valencia. ATLAS W path Masterclasses were organized at University of Calabria \& INFN Cosenza, University of Lund, University of Mainz, and Varginha (Brazil). The following institutes organized CMS Masterclasses: University of Debrecen, CIEMAT Madrid, Sapienza University Rome, University of Santiago de Compostela, SPRACE São Paulo. ALICE Masterclasses were held at iThemba Labs in Cape Town and at University \& INFN Cagliari. In Cagliari, physicists organized a LHCb Masterclass in addition.

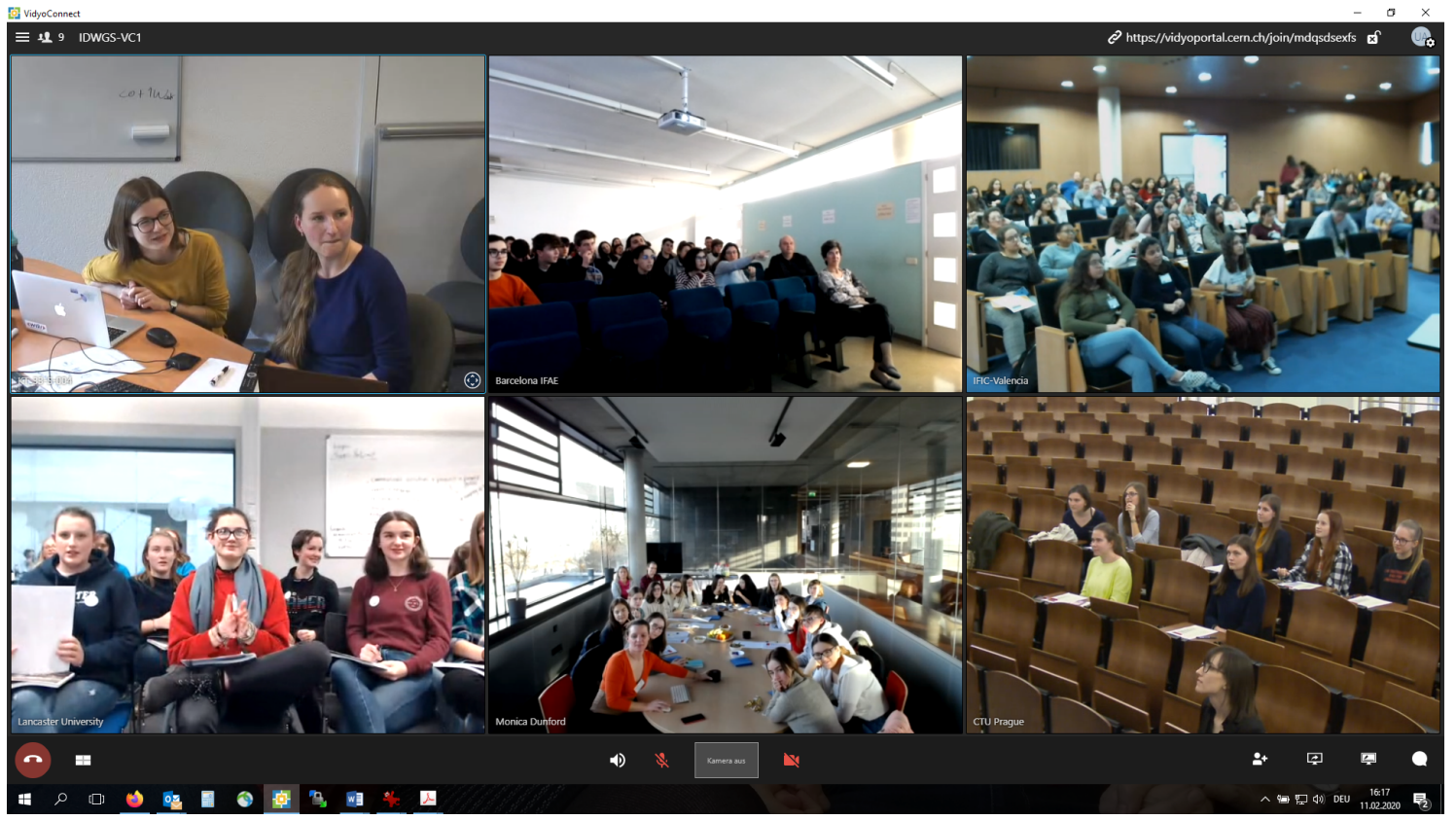

Figure 3: Screenshot from the videoconference with female physicists at CERN and groups in IFAE Barcelona, IFIC Valencia, CTU Prague, University of Heidelberg, and Lancaster University (clockwise from top left)

At CERN, eight female scientists joined the Masterclass groups in four videoconferences. They talked to the girls, discussed the groups' combined results, gave a presentation on the situation of women in physics, and answered the students' questions.

\section{Discriminating boys?}

When offering girls-only events, we obviously exclude boys from these Masterclasses. This has led to the question whether we discriminate against boys. First of all, it should be noted that the regular IMC program includes more than 220 Masterclasses every year, which are open to participants of all genders. The 17 Masterclasses within the IDWGS in 2020, 14 of which were only for girls, are an additional offer.

In principle, a normal Masterclass is free to access for girls and boys. Offering the same to both genders is usually referred to as equality approach. But this does not mean they actually have an equal chance to participate. Girls might need extra encouragement. With our special offer of girls' Masterclasses we implement the equity approach, address some of the structural inequalities and recognize that the situations for boys and girls in society are different. A cartoon that illustrates the difference between equality and equity approach can be found at [12]. The illustration deals with differences in physical attributes, but can be easily extended to other attributes. 


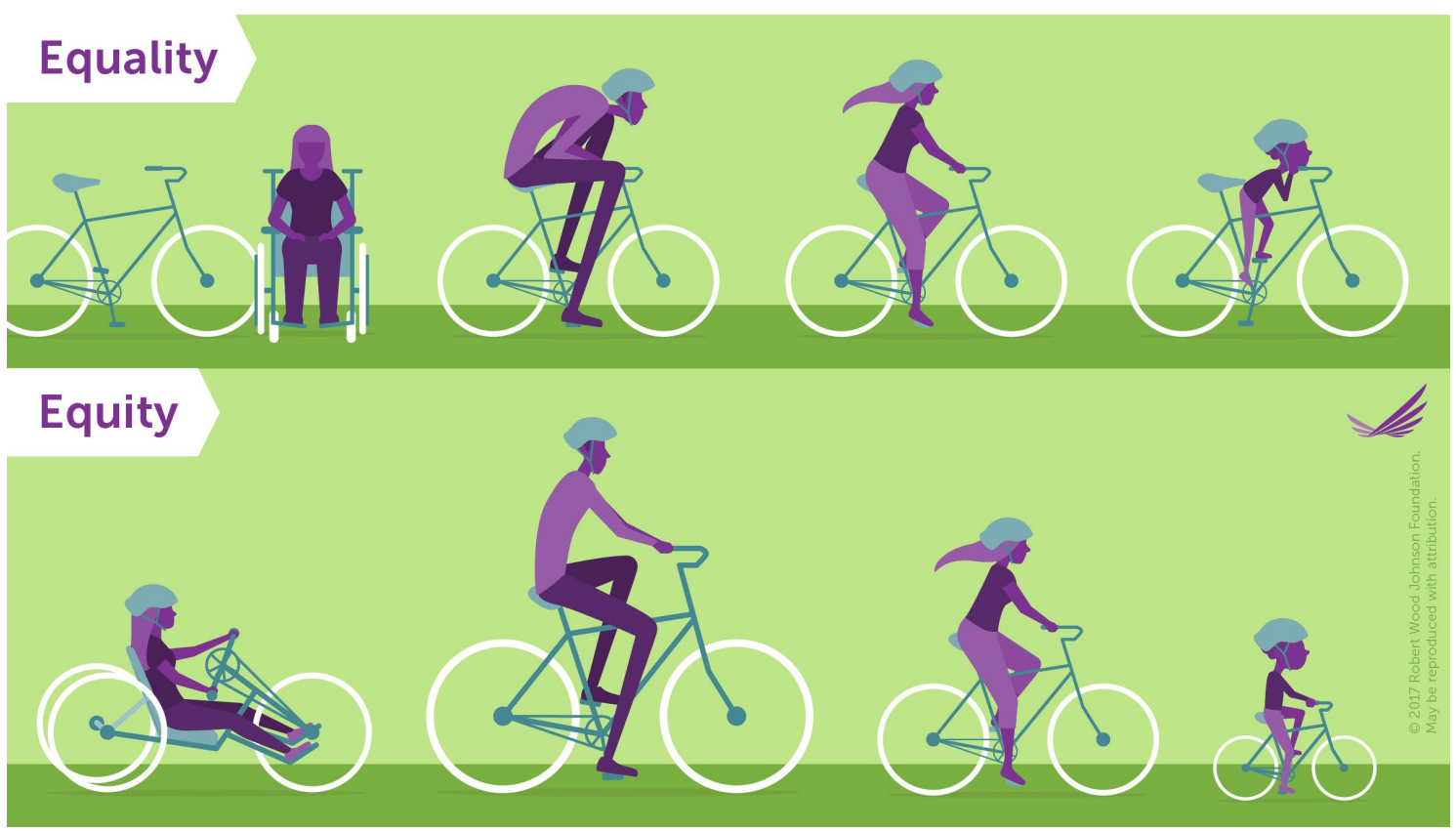

Figure 4: Visualizing equity: one offer might not fit all (C) Robert Wood Johnson Foundation)

\section{Conclusion}

IPPOG has been organizing special Masterclasses for girls for four years. At these events, female students can learn about the research field of particle physics, work on research tasks themselves, and meet role models. Research institutes from three continents have participated in previous editions, and interest is growing. Apparently, more and more institutions are recognizing the need to address the low proportion of women in physics with special offers and to increase equal opportunities for all genders.

\section{References}

[1] https://www.physicsmasterclasses.org/.

[2] M. Bardeen, H.P. Beck, U. Bilow, K. Cecire, F. Ould-Saada, M. Kobel, International Masterclasses in the LHC era, CERN Courier May 22, 20,

https://cerncourier.com/a/international-masterclasses-in-the-lhcera/.

[3] https://ippog.org.

[4] P. J. Mulvey, S. Nicholson, Physics Bachelor's Degrees: 2018,

https://www.aip.org/statistics/reports/physics-bachelors-degrees2018 .

[5] A. M. Porter, R. Ivie, Women in Physics and Astronomy, 2019,

https://www.aip.org/statistics/reports/women-physics-and-astronomy2019 .

[6] L. Archer, J. Moote, E. MacLeod: Learning that Physics is 'Not for Me': Pedagogic Work and the Cultivation of Habitus among Advanced Level Physics Students, Journal of the Learning Sciences, DOI : $10.1080 / 10508406.2019 .1707679$. 
[7] https://www.un.org/en/observances/women-and-girls-in-science-day/.

[8] https://physicsmasterclasses.org/index.php? cat =archive\&page=women_in_science_2017.

[9] https://physicsmasterclasses.org/index.php? cat=archive\&page=women_in_science_2018.

[10] https://physicsmasterclasses.org/index.php? cat=archive\&page=women_in_science_2019.

[11] https://physicsmasterclasses.org/index.php? cat=archive\&page=women_in_science_2020.

[12] Robert Wood Johnson Foundation https: / /www.rwjf.org/

[13] A special thanks to Beth Bramley, Gender Balance Manager at IOP, for valuable discussions. 